\title{
ADQUIRIENDO EXPERIENCIAS Y NUEVOS DESAFIOS
}

Pablo Mauricio Pachas

E-mail: pwmauricio@yahoo.es

\section{RESUMEN}

En la presente investigación se destaca la formación de profesionales en economía, administración y negocios en las Universidades de reconocido prestigio internacional; a propósito de la invitación por el Departamento de Estado de los Estados Unidos.

Tales experiencias plantean desafíos para la Universidad Publica de nuestro País en la formación del nuevo profesional de economía, administración y negocios, que respondan al contexto de cambios y a la elevada competitividad de los mercados; en donde vienen destacando los países de Asia e India con su innovación y creatividad. Cuyo propósito será fortalecer al sector empresarial dedicado al comercio exterior, que en los últimos 5 años han venido generando importantes saldos en la balanza comercial para el beneficio del país. La Universidad debe aportar profesionales involucrado en la empresa y en la realidad económica, para fortalecer las potencialidades de las regiones que dedican su producción a las exportaciones no tradicionales y al desarrollo del País.

Palabras clave: Elevada, fortalecer, desafío.

\begin{abstract}
In the present study the formation of professionals in economy stands out, administration and businesses in the Universities of recognized international prestige; with regard to the invitation by the Department of State of the United States. Such experiences raise challenges for the University Publishes of our Country in the formation of the new professional of economy, administration and businesses, that respond to the context of changes and to the high competitiveness of the markets; where they come emphasizing the countries from Asia and India with his innovation and creativity. Whose intention will be to fortify to the enterprise sector dedicated to the foreign trade, that in the last 5 years has come generating important balances in the trade balance for the benefit from the country. The University must contribute professionals involved in the company and the economic reality, to fortify the potentialities of the regions that dedicate their production to the nontraditional exports and to the development of the Country.
\end{abstract}

Keywords: Elevated, to fortify, challenge.

\footnotetext{
Magíster en Economía, Estudios de Doctorado de la Universidad Nacional Mayor de San Marcos. Economista. Especialización en Finanzas, Planeamiento y Proyectos. Consultor de Negocios Bursátiles y Profesor Principal, Director de la Escuela de Negocios Internacionales (UNMSM). Docente de Maestría en UNMSM, Universidad Nacional de Ingeniería, Universidad de Tacna, entre otras.
} 


\section{INTRODUCCIÓN}

El mundo en las últimas décadas ha cambiado rápida y dramáticamente, produciendo cambios paradigmáticos, estructurales, la interconexión inmediata de los espacios físicos está prácticamente al alcance de un click.

En visita a las principales universidades de la costa este de Estados Unidos (Pace University, New York University, The Levin Institute, Columbia University, Yale University, Northeastern University, Boston University y Suffolk University), invitación realizada por el Departamento de Estado de dicho país, en el marco del Internacional Visitor Leadership Program, me ha dejado una sensación de conflicto: iestamos yendo a la velocidad necesaria para alcanzar pronto un nivel de competitividad académica acorde con las exigencias del siglo XXI? A continuación intentaré transmitir de manera sucinta mis impresiones sobre este fascinante periplo.

Se puede obtener una perspectiva general del modelo estadounidense de educación superior relacionado con la empresa y mercados, a través de las universidades visitadas que cuentan con diversos programas de especialización para las áreas de Administración, Contabilidad, Economía y Negocios. Todas hacen énfasis en los programas de Post Grado, profundizando la información y actualización constante en las áreas en mención, y el desarrollo curricular de los mismos presta mucha atención al marco teórico y a sus aplicaciones prácticas en la realidad, haciendo énfasis en finanzas, liderazgo, creatividad e innovación.

\section{REDUCIENDO LAS FRONTERAS}

En este tiempo de economías sin fronteras, donde los medios de comunicación y los sistemas nos acercan cada vez más, se torna imperativo propiciar encuentros y visitas con académicos de otras latitudes. El enfoque global que se encuentra en las universidades norteamericanas, propio de la primera economía mundial, nos indica que el camino de la internacionalización es necesario. Por ejemplo, el programa de Master of Business Administration (MBA) de la Universidad de Yale prevé visitas a varios países alrededor del mundo como Costa Rica, Argentina, Sudáfrica, Tanzania, Inglaterra, Polonia, China, India, Japón y Singapur.
Esta internacionalización va de la mano, necesariamente, con una creativa e innovadora exigencia académica. El 70\% de los alumnos de Post Grado en Estados Unidos son extranjeros, predominando los que provienen de China. Por ejemplo, en la Columbia Business School, el 75\% de estudiantes extranjeros son chinos e indios. Hoy en día Estados Unidos se orienta al mercado de Asia - Pacífico, el nuevo eje comercial de la economía mundial. Tanta es la importancia económica del gigante asiático que la Universidad Estatal de Nueva York ha implementado en China el Centro de Ciencia, Innovación y Tecnología del Instituto Levin.

La gran dimensión de los mercados chino e hindú constituyen una oportunidad de mercado para las Escuelas de Economía, Administración y de Negocios Internacionales, que deberán integrarse a esta tendencia. En cuanto a la Escuela de Negocios Internacionales de la Universidad Nacional Mayor de San Marcos (UNMSM) se presenta la paradoja que mientras nosotros implementamos un Centro de Investigación AsiaPacífico, las universidades del país del norte se trasladan con todo su potencial académico al mismo corazón de China, haciendo notar la gran capacidad económica con que cuentan.

Tal tendencia no hace sino confirmar la importancia de la presencia del Perú en el Foro de Cooperación Económica Asia-Pacífico (APEC) y lo trascendental que será para el país el año 2008 , momento en el que ejerceremos la presidencia del Foro y seremos sede mundial del encuentro anual de los países mimebros, horizonte promisorio para nuestros graduados en $\mathrm{Ne}$ gocios Internacionales.

También es significativo el número de hispanos en los centros de estudios de Estados Unidos (aproximadamente un 10\%), que confirma la importancia creciente que tiene la formación profesional internacionalizada la comunidad hispana. En el marco de la integración de la comunidad latina en los centros superiores de estudio del país del norte, encontramos programas intensivos y novedosos de enseñanza del inglés que permiten alcanzar, en sólo seis meses, un nivel de manejo del idioma acorde con las exigencias de la universidad, que permiten al estudiante integrarse a las clases sin desventajas ni complejos. 
La práctica de la tolerancia con las minorías étnicas y la presencia de éstas a nivel estudiantil y docente no hace sino confirmar el rol de los Estados Unidos como crisol de razas y beneficiario de los aportes que todas las culturas han brindado para su desarrollo. En ese aspecto es de destacar la presencia -a nivel estudiantil y docente- de personas provenientes de países que actualmente tienen conflictos con esta potencia mundial, pero que gozan de la simpatía, aprecio y reconocimiento de la comunidad universitaria.

\section{LA UNIVERSIDAD FRENTE A LA REALIDAD}

En paralelo al desarrollo intelectual y tecnológico acelerado, se han ahondado las distancias sociales. Los niveles de acumulación de riqueza en las sociedades capitalistas son -desde mi punto de vista- inequitativos, en contraste con las mayorías empobrecidas del tercer mundo, por lo que concluyo que los pobres son cada vez más numerosos y más pobres, mientras que los ricos son cada vez menos y tienen mayor acumulación de dinero.

Estas reflexiones nos permiten entender que el reto que tenemos por delante -de generar una educación más justa y equitativa, que coadyuve al desarrollo de los pueblos- debe ser encarado con responsabilidad y esperanza, para acompañar adecuadamente los cambios que experimentan los mercados. Aún existen esos milagros inesperados que significan las nuevas tecnologías del conocimiento que dan al hombre una esperanza, porque permiten que el saber se ponga al alcance de los que menos tienen, además de facilitar nuestra inserción en las ligas mayores del conocimiento, lo que nos lleva a todos a mirar a nuestro alrededor, aprendiendo de los demás y compartiendo experiencias que favorezcan a todas las partes involucradas.

Y aunque suene a perogrullada, es en la educación desde donde debemos sustentar la construcción del desarrollo de nuestro país. Lo que desconcierta es que sabiendo que esto es cierto ¿por qué no se empieza? Tal vez porque en nuestros gobernantes predomina una visión individualista y un precario compromiso con el desarrollo del país. Frente a esta preocupación de ir revirtiendo este escenario, se debe promover una real y actual formación de nuestros profesionales, para que la universidad pública deje de estar a espaldas de la realidad y desterrar la errónea concepción de que lo público es irremediablemente malo, a veces innecesario y siempre ineficaz.

En tal sentido se ha establecido contactos y acercamientos que podrían contribuir a la mejora de la formación académica de nuestros nuevos profesionales vinculados a la empresa, siendo necesario que los nuevos planes curriculares de Economía, Administración y Negocios Internacionales incluyan por lo menos tres asignaturas que se dicten totalmente en inglés, porque somos conscientes de la necesidad del manejo de este idioma para incursionar sin cortapisas en el mundo. Asimismo pronto será un imperativo exigir un nivel básico de chino mandarín para optar la licenciatura profesional.

\section{MEDIO AMBIENTE Y PRODUCTOS ORGÁNICOS}

En cuanto a la preocupación ambiental como un tema global de primer orden, se desprende la necesidad de afrontar esta problemática de manera científica y, sobre todo, bajo el compromiso del empresario de reducir la emisión de sustancias contaminantes en los procesos productivos de las empresas y en nuestro comportamiento como consumidores.

Para el Perú, por ser un país con una gran biodiversas, se abre no sólo un impresionante abanico de oportunidades para el aprovechamiento racional de nuestros innumerables recursos ambientales y genéticos -oportunidad que debe incluirse en la formación de nuestros profesionales- sino también una obligación para con la protección, conservación y explotación sostenida y sostenible de estos recursos.

Atentos a las tendencias del consumo mundial, que reclama cada vez más productos orgánicos y ambientalmente certificados, nos toca-como Escuela de Negocios Internacionales- generar un compromiso ético en los alumnos y egresados que concuerda con el compromiso de incluir en los planes de estudio de Pre Grado temas ambientales formadores de conciencia y de respeto de los derechos de las generaciones venideras a tener un mundo limpio. En este sentido se debe fortalecer el comercio exterior que ha venido creciendo favorablemente en los últimos cinco años por las altas cotizaciones de los minerales y por el incremento de la agroexportación y de las exportaciones no tradicionales. 


\section{INNOVACIÓN Y CREATIVIDAD}

Para nadie es un secreto que la imaginación y la creatividad son los principales activos de las organizaciones en esta era del conocimiento, activos que alcanzan su máxima capitalización cuando se transforman en productos y servicios novedosos de gran aceptación en el mercado. Recordemos que son numerosas las voces que nos hablan de un paso de la "era del conocimiento" a la "era de la creatividad", por lo que resulta imprescindible que el país invierta sendos recursos en el conocimiento y la educación.

En los centros de estudios norteamericanos existe una sólida vinculación entre la universidad y la empresa, donde esta última otorga un importante soporte a la investigación aplicada y promoción de incentivos a los docentes investigadores. Las empresas muchas veces transfieren sus proyectos de investigación y desarrollo a las universidades y éstas, con la tranquilidad que brinda el soporte económico con que cuentan, encuentran soluciones y descubren nuevos horizontes que después se traducen en productos o servicios que las empresas llevarán con éxito a los mercados locales y globales.

Para tener una idea de la magnitud del apoyo de la empresa privada a la universidad mencionaremos algunos de los premios que han otorgado organizaciones privadas a la Universidad de Yale para realizar investigaciones, como la Fundación Landers que entregó US\$ 150,000 en 1981, o el Roche's Leadership Development Program que otorgó US\$ 25,000 en el 2004. Lo anterior refuerza la idea de buscar un mayor acercamiento entre la universidad pública y el empresariado nacional.

Ante la importancia de que el estudiante lea e investigue para alcanzar los niveles de competitividad que el mercado exige, es necesario contar con bibliotecas especializadas que se renueven para que los alumnos tengan el soporte adecuado para su formación académica.

Es por ello que encontrar bibliotecas con más de 800,000 volúmenes como el caso de Pace University suena increíble, pero tal vez más increíble es que su videoteca cuente con una cifra similar de producciones para uso académico, y por si fuera poco, está suscrita a más de 4,000 revistas especializadas. Esto corrobora la importancia de las imágenes como elemento de apoyo en la labor docente y la necesidad de fomen- tar el uso de material fílmico para conseguir un mejor resultado en el alumnado. Adicionalmente a ello existen numerosos "libros electrónicos" de uso libre en la web, que están al alcance de todo aquel que desee tenerlos; por ello es importante establecer el compromiso de los docentes para utilizar el "Campus Virtual" de la facultad y promover cursos on line que permitan que los peruanos de cualquier rincón del país puedan acceder al conocimiento, logrando de paso recursos para la universidad y para los propios docentes.

Cabe también la necesidad del seguimiento estadístico de los egresados de nuestros centros de estudios, tal como sucede en los Estados Unidos, donde registran la colocación laboral de sus graduados en MBA, en trabajos acordes con su calificación, colocación que llega al $90 \%$ de cada promoción dentro de los primeros noventa días posteriores a su graduación. Este tipo de información es un buen indicador para determinar la pertinencia de los programas curriculares, tanto en el Pre Grado como en el Post Grado, respondiendo a la pregunta de si estamos formando empresarios o empleados calificados.

\section{CERTIFICACIÓN}

Hoy en día la mayoría de los centros de formación académica de cualquier parte del mundo tienen como objetivo alcanzar una certificación internacional de excelencia mediante la acreditación, que no sólo significa prestigio para el centro de estudios sino que también permite la movilidad de estudiantes entre estos centros certificados, por lo que resulta imperativo que la UNMSM obtenga este tipo de acreditaciones.

La acreditación es el medio de autorregulación y revisión precisa adoptada por la comunidad educativa, y está enfocado en fortalecer y sostener la calidad de la educación superior, haciéndola merecedora de la confianza pública y minimizando la perspectiva del control externo. Par tal fin las universidades norteamericanas han desarrollado requisitos de elegibilidad y 14 estándares para la obtención de dicha acreditación (tema a desarrollar en un próximo artículo), por lo que cabría revisar con cuantos de estos estándares estaríamos cumpliendo en nuestra universidad para que en el futuro pudiéramos obtener estos beneficios de calidad 
académica. No debe perderse de vista que la certificación tiene como correlato una posición en el ranking de las universidades como es el caso de Northeastern Universtity, que ocupa la décimo novena ubicación en el ranking de Facultades de Negocios Internacionales.

Nuestro país, imbuido en un proceso de descentralización definido por ley como irre- versible, pronto requerirá contar con cuadros profesionales de elevada calidad académica que respondan a la necesidad de una administración moderna y eficaz a lo largo y ancho del Perú. Adicionalmente los egresados de las facultades de ciencias empresariales deben tener como finalidad ayudar a reducir la brecha que separa a los ricos de los pobres; solo así estaremos contribuyendo con el desarrollo del país. 